\title{
Desenvolvimento do pensamento computacional por meio da Ciência da Computação Desplugada e do Scratch
}

\author{
Developing computer thinking through Unplugged Computer Science and Scratch
}

Patricia Cristina Venturini ${ }^{1}$

\section{RESUMO}

Este trabalho relata uma atividade de extensão, desenvolvida pela Universidade Federal de Uberlândia em uma escola pública da cidade de Ituiutaba, Minas Gerais, no âmbito do projeto "Pensamento Computacional na Escola", tendo como intuito estimular e desenvolver o pensamento computacional de crianças do sexto ano do ensino fundamental. Abordagem de Ciência de Computação Desplugada e ferramenta de programação Scratch foram utilizadas para este fim. Ficou evidenciado que atividades desplugadas servem de apoio e agente facilitador para compreensão e criação de programas computacionais. A falta de maturidade da maior parte das crianças nessa faixa etária exige que, inicialmente, as atividades de programação aconteçam de forma guiada.

Palavras-chave: Pensamento computacional. Ciência da computação desplugada. Scratch.

\begin{abstract}
This work reports an extension activity, developed by the Federal University of Uberlândia, in a public school in the city of Ituiutaba, State of Minas Gerais, within the scope of the Computational Thinking at school project, aiming to stimulate and develop the computational thinking of sixth grade children in middle school year. Unplugged Computer Science approach and Scratch programming tool were used for this purpose. It was evidenced that unplugged activities help in the support and facilitating agent for the comprehension and creation of computer programs. The lack of maturity of most children in this age group requires that, initially, programming activities take place on a guided basis.
\end{abstract}

Keywords: Computational thinking. Unplugged computer science. Scratch.

\section{Contexto do Relato}

A difusão e utilização de tecnologias na educação brasileira passaram a ser asseguradas e exigidas a partir de 1996 com a Lei de Diretrizes e Bases (LDB) (BRASIL, 1996). Em 1997, foi lançado, pelo Ministério da Educação, o Programa Nacional de Tecnologia Educacional (ProInfo) pela Portaria no 522 (BRASIL, 1997), no intuito de promover o uso pedagógico das tecnologias de informática e comunicações na rede pública de ensino fundamental e médio.

\footnotetext{
${ }^{1}$ Doutora em Física pela Universidade Federal de São Carlos, São Paulo, Brasil; professora adjunta da Universidade Federal de Uberlândia, Campus Pontal, Minas Gerais, Brasil (pcventurini@ufu.br).
} 
Em 2014, foi sancionada a Lei 13.005/2014, conhecida como Plano Nacional de Educação (PNE) (BRASIL, 2014). Essa lei, de duração decenal, traz em seu âmago um conjunto de metas a serem alcançadas no intuito de erradicar o analfabetismo, melhorar a qualidade da educação, além de valorizar os profissionais da educação brasileira. Ficaram estabelecidas, assim, ações conjuntas, em regime de colaboração entre os poderes públicos das diferentes esferas federativas, objetivando assegurar e desenvolver o ensino em todos os seus níveis e modalidades no país. Seria uma espécie de parceria, articulada entre União, os estados, o Distrito Federal e os municípios, no intuito de promover o aperfeiçoamento do sistema educacional brasileiro. Dentre as estratégias previstas no PNE estava um aumento considerável (triplicação) da relação computador/aluno nas escolas da rede pública de educação básica, de modo a promover a utilização das tecnologias da informação e da comunicação.

Vemos, de fato, que o uso de tecnologias está presente em nosso dia a dia e que, muitas vezes, nos tornamos dependentes dela. As escolas estão se equipando de computadores como ferramentas de apoio ao ensino, porém, segundo KOLOGESKI et al. (2016), a forma como têm sido utilizados não exige grandes desafios lógicos, uma vez que, normalmente, são usados para a realização de pesquisas, formatação de trabalhos, realização de cálculos em planilhas, e atividades que, em geral, são de conhecimento básico, operacional.

Não faz sentido, diante da possibilidade de acesso full-time a dados e a informações, que se priorize a memorização, a repetição e a cópia pela cópia. Pelo contrário, o mais importante é ensinar a buscar e a selecionar a informação necessária, abstrair, decompor, reconhecer padrões e programar para que o aluno possa, de modo criativo e dinâmico, enfrentar os problemas propostos em determinada circunstância, através do pensamento crítico e uma metodologia para auxiliar no processo de resolução de problemas. (BRACKMANN, 2017, p. 20).

Claramente, é preciso que se faça uma distinção entre usar ferramentas computacionais e ter a habilidade do Pensamento Computacional. A primeira trata de uma capacidade operacional, enquanto a segunda diz respeito à habilidade intelectual de estruturar problemas e encontrar soluções para os mesmos. Wing (2006) definiu Pensamento Computacional como a utilização de conceitos fundamentais à ciência da computação como ferramentas mentais para solucionar problemas, projetar sistemas e compreender o comportamento humano.

Este trabalho descreve uma atividade realizada em uma instituição educacional pública da cidade de Ituiutaba, Minas Gerais, no primeiro semestre de 2019, como parte do projeto de 
extensão "Pensamento Computacional na Escola", desenvolvido pela Universidade Federal de Uberlândia. A ferramenta de programação de computadores Scratch, bastante difundida no processo de aquisição das habilidades do Pensamento Computacional (COSTA; AZEVEDO; MADEIRA, 2018), foi trabalhada com 12 alunos do sexto ano do ensino fundamental da referida escola. Nesse processo, verificou-se a necessidade de se complementar as atividades trabalhadas fazendo uso da Computação Desplugada, isto é, por meio de elementos de fácil acesso e de atividades lúdicas, sem a preocupação com as dificuldades e distrações que um computador pode ocasionar (BELL; WITTEN; FELLOWS, 2011).

\section{Detalhamento das atividades}

Foram selecionados, pela direção da escola, um total de 20 alunos do sexto ano do ensino fundamental, integrantes de quatro turmas diferentes. A direção da escola não revelou os critérios de seleção para a coordenação desse curso, de modo que, acabaram compondo o grupo de alunos selecionados crianças tidas com maior e menor desempenho na sala de aula. Foi disponibilizado para uso de cada uma delas um notebook com acesso à internet. O curso teve duração de 12 semanas com duração de uma hora e meia em cada semana.

No primeiro dia de curso, compareceram à aula 13 alunos. Foi-lhes apresentada a ferramenta de programação Scratch, explicado sem maiores detalhes cada recurso da mesma e, por fim, criados, de forma guiada, programas computacionais explorando algumas de suas funcionalidades.

Nesta etapa, foram evidenciadas algumas dificuldades por parte dos alunos, das quais citaremos duas por parecerem mais relevantes. A primeira delas diz respeito à compreensão de que o computador consegue realizar apenas tarefas que lhe são ensinadas, passo a passo e de forma sequencial. Os alunos tiveram dificuldade de compreender que o computador não é capaz de "adivinhar" o que o programador quer que ele faça, apenas segue instruções passadas. Tendo em vista que os programas criados no Scratch são obtidos a partir de blocos de instruções que se encaixam uns aos outros, não gerando mensagens de erros, os alunos começaram a dispor os blocos encaixados aleatoriamente, sem qualquer controle sobre o programa que estavam criando.

A segunda dificuldade é referente ao fato do Scratch, sendo um ambiente de visualização gráfica em que são criadas animações, trabalhar com sistemas de coordenadas cartesianas. 
Apesar de estar previsto na Base Nacional Comum Curricular (BRASIL, 2018), a partir do quinto ano do ensino fundamental, as primeiras noções de coordenadas cartesianas, os alunos participantes desse curso tiveram grande dificuldade de compreensão e uso das mesmas.

Entendendo que essas dificuldades precisavam ser sanadas logo no início, a coordenação do curso optou por utilizar, no segundo dia de aula, a metodologia da Computação Desplugada. Duas atividades foram, então, desenvolvidas utilizando apenas papel e caneta com os 12 alunos que compareceram. A primeira visava exemplificar que os computadores seguem as instruções ao pé da letra, ainda que produza resultado não desejado, e está proposta no livro Computer Science Unplugged (BELL; WITTEN; FELLOWS, 2011). Para exemplificar, a ministrante do curso deu instruções aos alunos de como reproduzir um desenho que estava em um cartão que só ela poderia ver. Cada aluno faria seu próprio desenho utilizando papel e caneta que foram distribuídos, seguindo as orientações transmitidas. A Figura 1 apresenta o desenho descrito pela ministrante. As instruções passadas foram as seguintes: a) Desenhe um ponto no centro do papel; b) Começando da ponta superior esquerda da página, trace uma linha reta passando pelo ponto até a ponta inferior direita; c) Começando da ponta superior direita da página, trace uma linha reta passando pelo ponto até a ponta inferior esquerda; d) Escreva seu nome no centro do triângulo do lado esquerdo do papel.

Figura 1 - Imagem contida no livro Computer Science Umplugged



Fonte: BELL; WITTEN; FELLOWS (2011).

Para um melhor entendimento da atividade, a ministrante precisou responder a algumas perguntas técnicas como: O que é superior e inferior? Qual é o lado direito e o esquerdo? 
Feito isso, os alunos compreenderam o que deveriam fazer e conseguiram realizar a atividade a contento. Em seguida, um aluno que estava animado com a aula foi escolhido para dar as instruções para seus colegas de como deveriam desenhar uma imagem que só ele poderia ver. A Figura 2 é uma representação da imagem descrita por ele.

Figura 2 - Imagem descrita na atividade

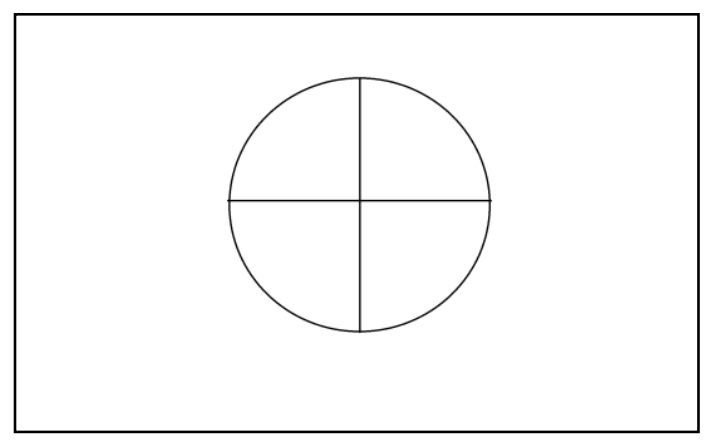

Fonte: A autora (2019)

O aluno criou e transmitiu as instruções a seguir:

a) Desenhe uma bola.

Indagado por seus colegas a respeito do tamanho da bola, o aluno respondeu que era média. Nesse momento, alguns alunos pediram para receber um novo papel porque tinham feito de tamanho errado.

b) Desenhe um X no meio da bola.

Quando os colegas terminaram, compararam seus desenhos com o do aluno que estava passando as instruções. Vários estavam diferentes do modelo e alguns ficaram chateados, pois não "acertaram" o desenho. A ministrante explicou que a atividade era apenas uma analogia ao funcionamento do computador e que eles tinham "acertado", pois tinham seguido corretamente a instrução passada pelo "programador". A questão estava em como criar um programa capaz de produzir o resultado desejado.

A segunda atividade foi inspirada no "Jogo da Conquista", proposta por Costa, Azevedo e Madeira (2018), que trabalha o sistema de coordenadas cartesianas utilizando o mapa-múndi e estabelece alguns objetivos de conquista para os jogadores. Diferentemente do jogo citado, cada aluno recebeu um papel em que estava impresso a grade do sistema de coordenadas e 
navios da própria biblioteca de palcos e personagens do Scratch. Essa atividade foi nomeada de "Batalha Naval" e sua esquematização está representada na Figura 3.

Figura 3 - Imagem ilustrativa do jogo de Batalha Naval construído a partir da ferramenta Scratch

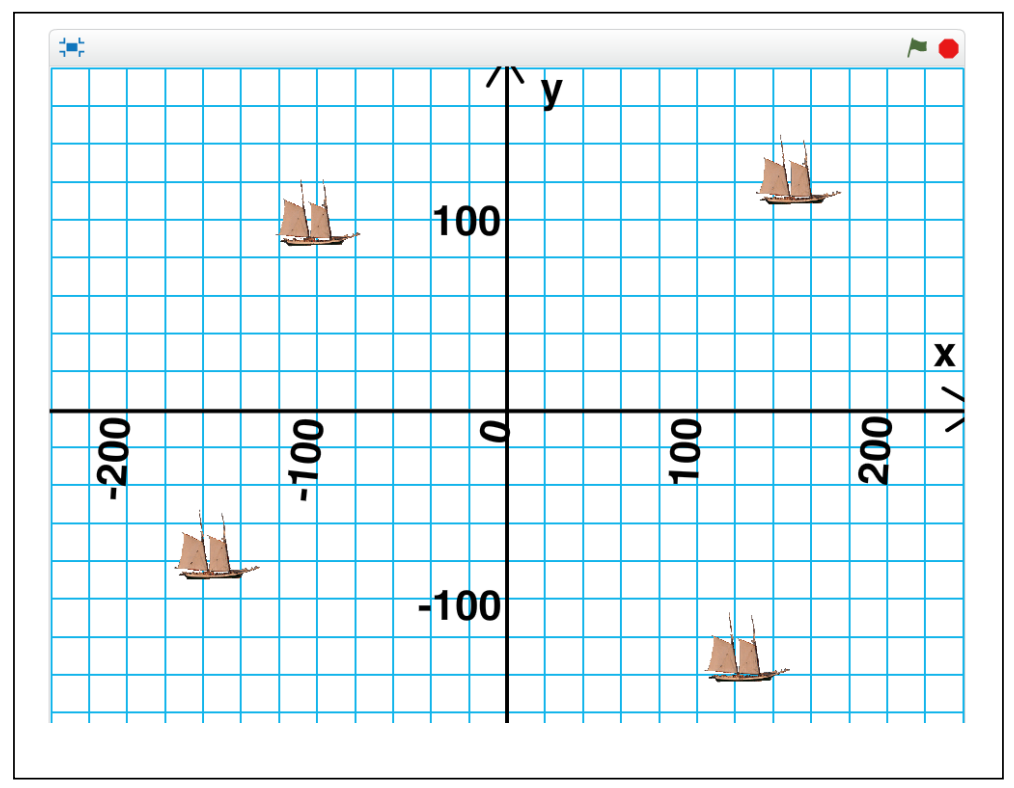

Fonte: A autora (2019).

A novidade aqui está no fato de se misturarem elementos do tradicional jogo de batalha naval, de fácil compreensão, com aquele que se pretendia ensinar, no caso o sistema de coordenadas cartesianas, utilizando imagens da ferramenta de programação Scratch.

Os alunos se posicionaram em pares, frente a frente, cada um com uma configuração de disposição de navios. Um aluno precisava adivinhar a posição do navio adversário informando uma coordenada $(x, y)$. Se na coordenada informada existisse alguma parte de navio do adversário, o aluno que adivinhou a posição pontuava. Os alunos de cada par revezaram-se em tentar pontuar e, ao final de 15 minutos, aqueles de cada par que alcançaram maior pontuação venciam a brincadeira. Nessa atividade, a todo o momento foi solicitada a ajuda da ministrante para que se certificassem se tinham pontuado ou não. Ao final da aula, foi feita a devida correspondência entre o sistema de coordenadas do jogo de Batalha Naval e aquele utilizado no ambiente do Scratch.

\section{Análise e Discussão}

Ao final das atividades desplugadas, solicitamos que os alunos criassem um programa no Scratch explorando a movimentação de uma personagem. Verificamos que eles se esforçaram 
para cumprir a atividade e que tentaram cumprir o solicitado, ao invés de se vangloriarem por construírem um programa aleatoriamente como tinha ocorrido na aula anterior. Alguns alunos, inclusive, foram além e exploraram a criação de um programa com várias personagens que se movimentavam e interagiam entre si.

Nas aulas que se seguiram, pudemos observar que aqueles que haviam faltado à aula onde foram desenvolvidas as atividades desplugadas tiveram uma dificuldade maior de compreender o processo de estruturação de um programa computacional e, também, de trabalhar com o sistema de coordenadas cartesianas utilizado a todo o momento no Scratch. Essa disparidade entre os alunos, aliada ao fato de o Scratch nunca enviar mensagens de erros, uma vez que os blocos com as instruções encaixados sempre produzem um programa a ser visualizado, exigiu que até a nona aula os programas desenvolvidos precisassem ser construídos de forma guiada. Nas três últimas aulas do curso, os alunos estavam aptos, finalmente, a construir seus próprios programas, recebendo apenas uma orientação inicial do que se esperava que eles fizessem.

\section{CONSIDERAÇÕES FINAIS}

A abordagem de Programação Desplugada para se trabalhar o desenvolvimento do Pensamento Computacional revelou-se valiosa, uma vez que se utiliza de elementos corriqueiros no ambiente escolar, não necessitando de uma formação especializada em qualquer tipo de tecnologia para ser aplicada. O raciocínio lógico é explorado e estimulado sem a preocupação com o domínio de um computador ou com as distrações que ele pode oferecer. Entretanto, essa metodologia, por si só, não é suficiente para garantir que nossos alunos se tornem agentes responsáveis e transformadores do mundo em que vivem, dominando tecnologias. A Programação Desplugada serviu também como um apoio no ensino de sistema de coordenadas cartesianas. A aprendizagem por meio da atividade lúdica torna-se mais agradável e, aparentemente, mais fácil de ser assimilada.

A ferramenta Scratch, muito difundida em práticas que visam ao desenvolvimento do Pensamento Computacional, torna mais simples o processo de criação de programas computacionais, uma vez que disponibiliza blocos de encaixar com as instruções, que, conforme a disposição, geram um programa cujo resultado pode ser visualizado. Assim sendo, não existem mensagens de erros, diminuindo a frustração do programador. Espera-se que ele 
seja capaz de analisar o resultado obtido e produzir alterações em seu programa até alcançar o resultado esperado.

Por outro lado, a pouca maturidade de crianças do $6^{\circ}$ ano faz com que seus primeiros programas precisem ser guiados, para que eles não fiquem satisfeitos, simplesmente, com qualquer resultado obtido a partir da disposição aleatória dos blocos de instrução. A forma guiada deve persistir até que eles estejam aptos a compreender que eles próprios devem estar no controle do processo criativo.

O fascínio que jogos, em especial os de computador, despertam em nossos jovens e crianças pode sim ser utilizado como um catalizador no processo ensino-aprendizagem. Ao final do curso, os alunos perceberam que não eram mais meros usuários da tecnologia e estavam ansiosos para terem oportunidade de dar um próximo passo, aprendendo uma linguagem de programação de computadores.

\section{REFERÊNCIAS}

BELL, T., WITTEN, I. H.; FELLOWS, M. Ensinando ciência da computação sem o uso do computador. 2011. Disponível em: https://classic.csunplugged.org/wpcontent/uploads/2014/12/CSUnpluggedTeachers-portuguese-brazil-feb-2011.pdf. Acesso em: 20 ago. 2019.

BRACKMANN, C. P. Desenvolvimento do pensamento computacional através de atividades desplugadas na educação básica. 2017. 226 f. Tese (Doutorado em Informática da Educação) - Centro Interdisciplinar de Novas Tecnologias na Educação, Universidade Federal do Rio Grande do Sul Porto Alegre, 2017.

BRASIL. Ministério da Educação. Lei de Diretrizes e Bases da Educação Nacional. Lei no 9.394, de 20 de dezembro de 1996. Estabelece as diretrizes e bases da educação nacional. Brasília, DF, 1996.

BRASIL. Lei $n^{\circ}$. 13.005, de 25 de junho de 2014. Aprova o Plano Nacional de EducaçãoPNE e dá outras providências. Brasília, DF, 2014.

BRASIL. Ministério da Educação. Base Nacional Comum Curricular: educação é a base. 2018.

COSTA, K. P. C.; AZEVEDO, M.; MADEIRA, C. Facilitando o uso do Scratch por meio de atividade desplugada que introduz o estudo do plano cartesiano. In: CONGRESSO BRASILEIRO DE INFORMÁTICA NA EDUCAÇÃO, 2018, Porto Alegre. Anais [...]. Doi: 10.5753/cbie.wcbie.2018.778. 
KOLOGESKI, A. L. et al. Desenvolvendo o raciocínio lógico e o pensamento computacional: experiências no contexto do projeto logicando. RENOTE, Porto Alegre, v. 14, n. 2, 2016. Doi: 10.22456/1679-1916.70686.

WING, J. M. Computational thinking. Communications of the ACM, v. 49, n. 3, p. 33-35, march 2006. Doi: 10.1145/1118178.1118215.

Submetido em 14 de setembro de 2019.

Aprovado em 16 de novembro de 2019. 